\title{
STRUCTURING OF LOADING POINTS AND MAIN SKID ROAD IN CONDITIONS OF EXISTING ROAD NETWORK IN FOREST COMPARTMENT
}

\author{
Dr Konstantin Pavlovich Rukomojnikov* \\ Volga State University of Technology, Yoshkar-Ola, Russia
}

The article offers the technique of choice of rational variants of placing the main skid roads in the forest compartment. This technique allows to reduce the cost of construction of loading points, skid roads and skidding of timber. The method is characterized by complex analysis of the process of logging from multiple disparate cutting areas within boundaries of the forest compartment with existing network of forest roads. The algorithmic graph theory is used in the calculations for solving this problem. The proposed method is recommended for low-volume logging companies who rent plots in limited operational forest areas.

Key words: Forest compartment, Algorithm, Harvesting, Skidding, Flow sheet, Logway, Cutting area, Loading point, Graph theory

\section{INTRODUCTION}

When designing the area of each forestry in the Russian Federation it is divided into forest compartments. In the forests which are constantly tended the boundaries of forest compartments are indicated by straight section lines with trees and bush cut. These section lines must be regularly clear-cut. After forest taxation the territory of each forest compartment is divided into primary in-ventory items of forest, named stratums. The shape of cutting areas and logging sites is determined due to configuration of stratums included in their composition. Also, the relief of the stratums, the ravines, streams and other objects located on their territory are taken into account.

According to the rules of logging in the forests of the Russian Federation, several adjacent stratums of ma-ture stands can be assigned for cutting in the forest com-partment if their total area does not exceed the size of the cutting area established for the prevailing species of stand-ing wood.

If on the territory of a forest compartment there are multiple small-area stratums, this forest compartment is considered to be one cutting area. Loading points are constructed on roads and section lines constituting the perimeter of the forest compartment. They are provided with a common network of technological corridors for all kinds of works in the forest. The felling license is issued for this whole compartment.
One of the essential tasks of the forest sector connected with compiling of an optimal flow sheet for utilization of a forest compartment is a choice of an opti-mal transportation flow sheet for utilization of forest sites within its territory, which allows to reduce the costs of preparatory and main cutting operations [01, 02, 03, 04, 05].

\section{LITERATURE REVIEW}

The current research works into the efficiency of primary transportation network of a logging company $[06,07,08,09,10]$ are focused on a mathematical description of the techniques for distribution of main operational ele-ments for logging operations within separate cutting areas on the territory of a forest site but do not provide any op-portunity for solving such a task for a forest compartment as a whole.

The above mentioned studies lack analysis of different variants for distribution of hauling roads, main skid roads and loading points taking into account multiple cutting areas that are developed simultaneously within a forest compartment. It prevents from applying them effectively for utilization of forest sites on a compartment basis.

Thus, as a result of analyzing the existing studies the improvement of validation procedures for different variants of temporary transportation ways as well as the development of theoretical provisions for determining an optimal flow sheet for utilization of cutting areas taking into account 
all stratums to be cut within a forest com-partment have been found out to be necessary.

\section{MATERIALS AND METHODS}

One of solution procedures of similar tasks within the forest sector that involves a simultaneous analysis of numerous variants of possible operational solutions for the development of a forest territory can be the use of graph theory methods. The clearness of graph theory structure allows to make available solutions of different application tasks, to develop and diversify the ways of their solution.

The analysis of forest sites development on a compartment basis provides an opportunity for visual representation of the forest compartment and cutting areas within its territory as a scheme including links between certain pairs of vertices characterizing the main elements of the situation being analyzed, which are connected by edges. Different variants of distribution of loading points and cutting area sites can be assumed to be such vertices, and possible variants of a transportation network connecting these vertices (i.e. section lines, hauling roads, operational corridors, skid roads and skidding trails) can be assumed to be such edges. A similar representation of a forest compartment is an effective instrument for statement and solution of the tasks connected with its construction and distribution of main operational elements for all kinds of logging works on its territory.

Figure 1 shows an example of structuring of load-ing points and main skid roads within a forest compart-ment, it represents the diagram including the variants of distribution of loading points and transportation ways. The number of elements to be analyzed can be different and is designed in dependence of local conditions, such as the relief, soil conditions, spatial location of stratums which need different measures at different stages of their development, age classes and stand condition, existence of wetlands and clearings, etc. In order to receive results that reflect the real situation in a more precise way while constructing a flow sheet of a forest compartment with indication of sites within its territory it might be allowed to use an additional specification of their geometric parameters that is connected with division of all or a part of large prolate cutting areas into a number of smaller sites with their own "gravity centers" of works to be performed. The Figure given here shows such specification used for division of two stratums into sites, as a result we have cutting area sites with "gravity centers" indicated by the numbers 4,5 and $7,8,9$.

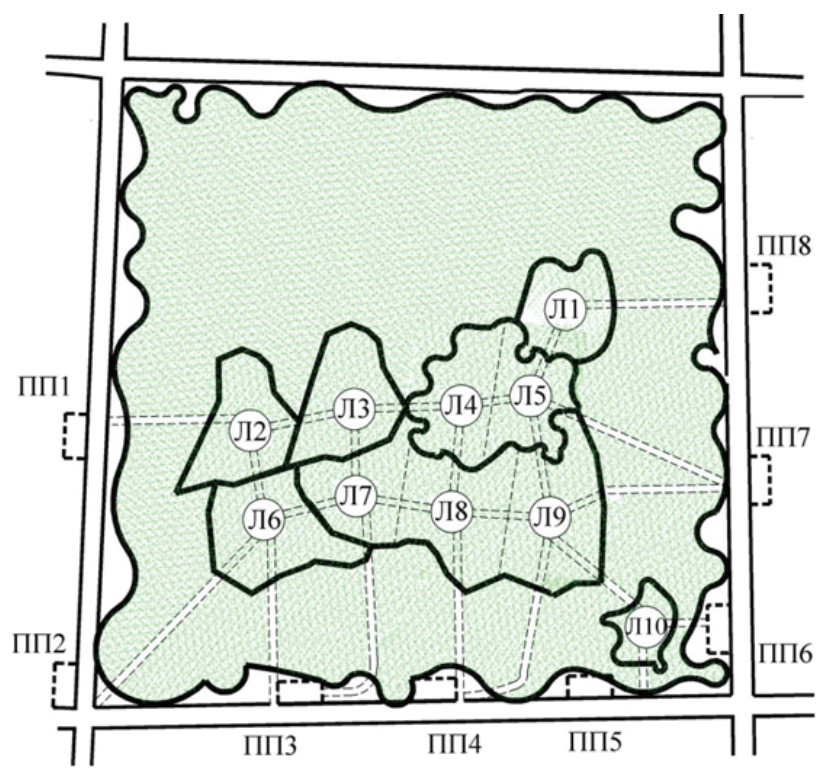

Figure 1: Statement of the task for provision of transportation way scheme in the forest compartment

All this variety has to provide the right choice for an optimal technology for development of the forest com-partment on the basis of maximum number of transporta-tion means implied by the algorithm.

For construction of the graph we can use the following references for the most possible places of loading points $\left(\Pi \Pi 1, \Pi \Pi 2, \ldots, \Pi \Pi i^{*}, \ldots \Pi \Pi k\right)$ the distribution of which is defined by an on-site investigation of the territory of a forest compartment from the point of view of the maximum account of the existing clearings, wetlands and other similar elements. Gravity centers of each site within a cutting area can be referred as $\Omega 1$, $Л 2, \ldots, \Omega i, \ldots . n$, then, on the graph we connect them with edges in accord-ance with the most possible direction of timber skidding.

The statement of the tasks suggests:

- The analysis of costs for construction of loading points $\mathrm{C} \Pi \mathrm{i}$;

- The definition of possible skidding distance staking into account the lengths of analyzed transportation ways of a preliminary transportation network;

- A back up calculation of possible costs for construc-tion of 1 long meter of each logway СПР, in dependence of natural conditions 
on the forest sites where they will be constructed;

- The definition of the cost of a machine-shift CT used by timber skidding.

The lines from a loading point to a logging site areas signed the value of $\mathrm{C} \Pi \mathrm{i}^{*}$, equal to the construction cost of a loading point necessary for this direction. The lines connecting loading points to each other and connect-ing logging site to each other are assigned the value $C \Pi \Pi=0$, meaning that usage of these transportation ways do not imply any loading point construction. This value allows to reduce the number of loading points as it is obviously that introduction of a new skid road into a graph implies additional expenses for construction of an adjacent loading point. All the vertices marking the loading points should be connected to each other by edges corresponding to compartment section lines, but should not form a closed loop.

Analyzing the existing algorithms of searching for a shortest spanning tree it should be noted that currently the most well-known Kruskal's, Prim's, Sollin's, Cheriton-Tarjan's algorithms cannot be applied to this situation as here we deal with an oriented graph which implies skidding only in the direction of loading points. At the same time Edmond's algorithm providing the opportunity of searching for a minimum weight spanning subtree and considering the graph vertices in random order cannot be applied in this situation either as the weights of edges making a spanning subgraph vary due to the set of edges constituting a spanning tree and connecting the vertex analyzed with its root.

The proposed algorithm for an optimal choice of a distribution scheme of transportation ways in the forest compartment allows to choose the shortest spanning tree for solution of a transportation subproblem in the forest compartment through growing one subtree of the graph (referred to as TS) with more than one vertex.

In practice of cutting operations in the forest compartment it is evident that the skidding distance and skidding costs should account the distance from the load-ing point of a previous site which is crossed by the skid-ding road. Thus, the special feature of the task of transportation way distribution in the forest compartment is that the weight of each edge to be connected to a subtree may not be known at the initial stage of the design process, but depends on the set of edges con- stituting the subtree at the previous steps of the analysis. The algorithm implies a consequent partial increase of the weight of each next edge to be connected to the graph subtree due to the weight of all edges connected to it earlier or due to the weight of a part of such edges.

\section{RESULTS AND DISCUSSIONS}

For implementation of the proposed algorithm the graph vertices are numbered so that the $x_{i}^{*}$ vertex corresponding to the spanning tree root would be numbered as $\mathrm{x}_{1}{ }^{*}$. Sow adopt $\mathrm{x}_{1}{ }^{*} \mathrm{CTS}$.

The costs of skid road construction, loading point construction and timber skidding from the $x_{i}$ forest site analyzed to the $x_{i}$ loading point can be found from the formula:

$$
C_{b i j}=L_{i j} \cdot C_{\Pi P i j}+C_{\Pi \Pi i j}+\frac{C_{T} \cdot V_{j} \cdot\left(T+\frac{2 \cdot L_{i^{*} j}}{v_{i^{*} j}}\right)}{3600 \cdot M \cdot m \cdot \varphi}
$$

where $L_{i j}$ is the distance between the $x_{i}$ and $x_{j}$ adjacent sites of the forest area, between these two adjacent sites the possible construction of skid road, $\mathrm{m}$, is analyzed; $\mathrm{C}_{\mathrm{ij}}$ is the construction cost of the skid road connecting the vertex analyzed (the cutting area site) with the previous vertex (the cutting area site), rubles; $\mathrm{C} \Pi \Pi_{\mathrm{ij}}$ is the construc-tion cost of the loading point for timber skidding from the $x$ site, rubles (to be indicated when the analyzed skid road (the edge) is adjacent immediately to the loading point (the $x_{i}$ vertex); CT is the cost of the skidding machine-shift, rubles/shift; $V_{j}$ is the stock to be cut out on the forest area analyzed, $\mathrm{m}^{3}$; $\mathrm{T}$ is the lab our contribution for collecting and unloading of a bundle of wood, sec; $L_{i}{ }^{*} j$ is the distance between the $X_{i}^{*}$ loading point and the analyzed $x$ site of the forest area, $m$; ui ${ }^{*} \mathrm{j}$ is the average motion speed of the machine used for skidding running in idle and freight-hauling directions on the site between the $x_{i}^{*}$ loading point and the analyzed $x_{i}$ site of the forest area, $\mathrm{m} / \mathrm{s} ; \mathrm{M}$ is the average volume of the skidded bundle of wood, $\mathrm{m}^{3} ; \mathrm{m}$ is the time of the shift, $\mathrm{H} ; \varphi$ is the shift time utilization rate.

Each vertex to be consequently connected to the TS subtree is assigned the [S;Cbij] mark. This mark includes the Si vertex which is a TS subtree vertex, the closest one to the xj vertex to be connected to the subtree, and Cbij is the weight of the graph edge to be connected and located between two vertices ( $\mathrm{Si} ; \mathrm{xj})$. 
Taking into account the existing hauling roads the vertices indicating the loading points are connected to each other with the edges up to achieving an incomplete loop already at the first step of the algorithm realization. So, we deduce:

$$
\begin{gathered}
T_{S}=x_{i^{*}}, x_{i^{*}+1, \ldots,} x_{k^{*}} ; \\
A_{S}=\left\{\left(x_{i^{*}}, x_{i^{*}+1}\right),\left(x_{i^{*}+1}, x_{i^{*}+2}\right), \ldots,\left(\left(x_{k^{*}-1}, x_{k^{*}}\right)\right)\right\}
\end{gathered}
$$

In the course of the further analysis the graph subtree is growing due to connection of the $\left(x i\left(\mathrm{xi}^{*}\right) ; \mathrm{xj}\right)$ edges, where $\mathrm{xi}\left(\mathrm{xi}^{\star}\right) € \mathrm{TS}$.

In every new iteration one of the vertices of the $\mathrm{xj} € \mathrm{TS}$ graph is connected to the TS subtree by adding the $(\mathrm{Si} ; \mathrm{xj})$ edge, or in order to avoid cycling the subtree is re-newed by replacing of one of its edge for the edge with a lower weight. The added edge should have the Cbij weight, the minimal one among the all TS subtree edges. When a new vertex is added to the TS subtree, there is a necessity of reviewing the [Si;Cbij] marks of all vertices adjacent to the latest vertex connected to the subtree. In such case both the adjacent vertices belonging to this TS subtree $x j € T S$ and the vertices not belonging to it $x j \in T S$ should be analyzed.

If the analysis results in a cycle including the existing edges of the subtree, i.e. the xj€TS vertex is found the weight of which can be reduced due to the following itera-tion, then the edge included in the knot at the previous iteration should be removed from the subtree. Further-more, the loop is open and all the vertices connected to the xj€TS vertex earlier by output directed edges are ex-cluded from the TS subtree and lose their marks.

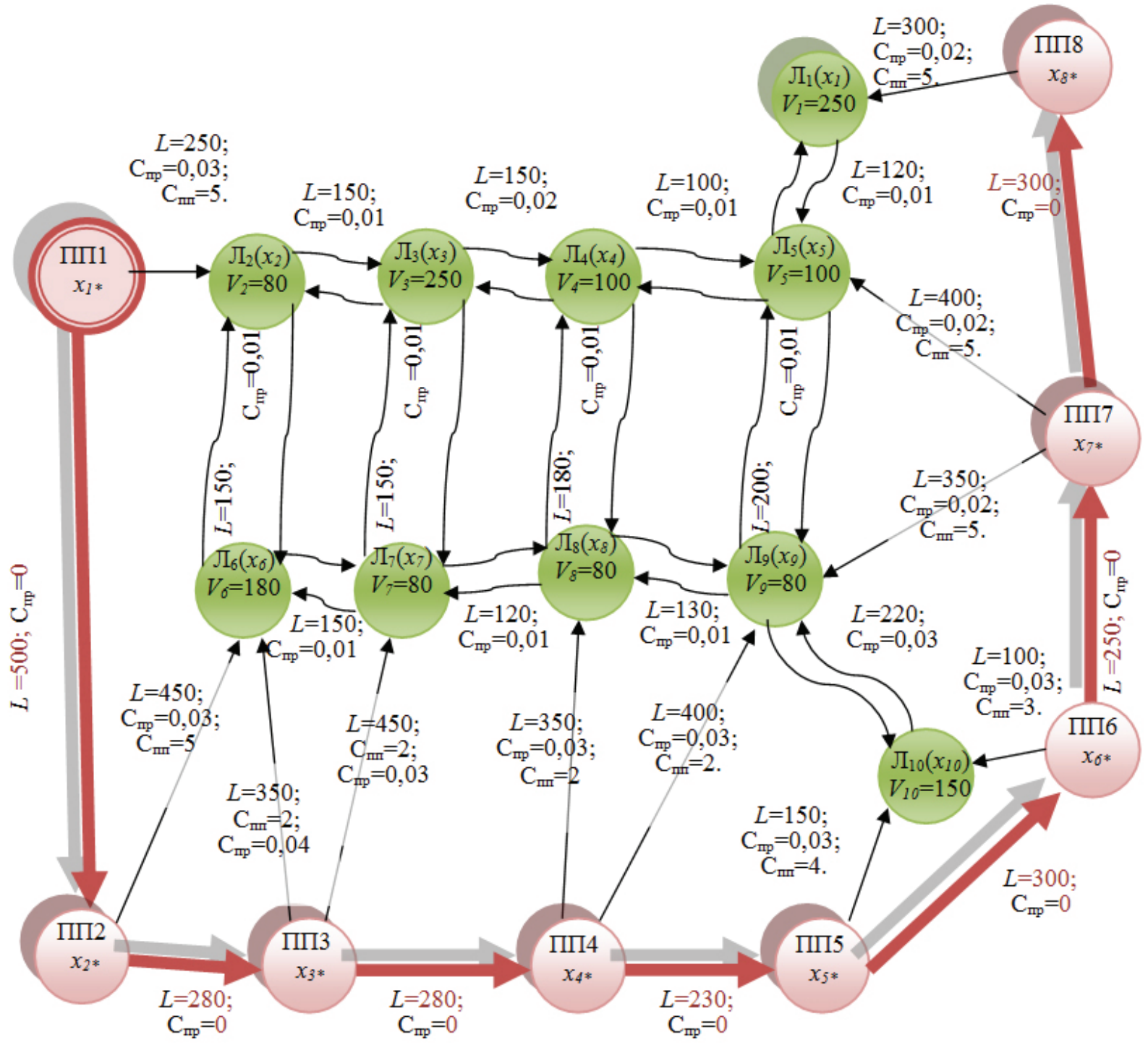

Figure 2: The graph and the given data for an example solution of the problem connected with the choice of transportation way distribution scheme 
The analysis should be continued until each vertex of the graph gets a mark whose weight would corre-spond to the minimal weight value among all its input oriented edge, and the number of the TS subtree edges equals to $k+n-1$ (where $n$ is a total number of the forest sites in the graph, $\mathrm{k}$ is a total number of the loading points in the graph). The resulted tree can be adopted as the shortest spanning tree graph, and, consequently, as the most rational variant of the logway distribution in the analyzed compartment.

\section{NUMERICAL EXAMPLE}

Now we consider an example solution of the task stated in Figure 1 assuming the following given data: $C T=6$ th.rub.; $M=7 \mathrm{~m}^{3} ; \mathrm{T}=1200 \mathrm{sec} ; \mathrm{m}=7 \mathrm{H}$; $\varphi=0,75$. The average motion speed of the machine used for skidding is adopted as equal for all the sites analyzed on the territory of the forest compartment $\mathrm{ui}^{*} \mathrm{j}=1 \mathrm{~m} / \mathrm{c}$. The given data asso-ciated with distribution of the transportation ways be-tween the sites are shown by Figure 2 .

The task is solved by the proposed algorithm.

Step 1.The analysis of the vertices indicating the loading points allows to suppose that the marks of these vertices equal 0 as there are no construction costs of transportation ways in these directions taking into account the existing hauling roads on the boundaries of the forest compartment, and, therefore, we can adopt the following as an initial subtree:

$T_{S}=\left\{x_{1}{ }^{*}, x_{2}{ }^{*}, x_{3}{ }^{*}, x_{4}{ }^{*}, x_{5}{ }^{*}, x_{6}{ }^{*}, x_{7}{ }^{*}, x_{8}{ }^{*}\right\}$;

$A_{S}=\left(x_{1}{ }^{*}, x_{2}{ }^{*}\right),\left(x_{2}{ }^{*}, x_{3}{ }^{*}\right),\left(x_{3}{ }^{*}, x_{4}{ }^{*}\right),\left(x_{4}{ }^{*}, x_{5}{ }^{*}\right),\left(x_{5}{ }^{*}\right.$, $\left.x_{6}^{*}\right),\left(x_{6}{ }^{*}, x_{7}{ }^{*}\right),\left(x_{7}{ }^{*}, x_{8}^{*}\right)$.

Step 2. The further analysis implies a consequent addition of vertices into the subtree, these vertices correspond to cutting area sites on the territory of the forest compartment. During this step the Cbij values for all the vertices located close to the vertex connected to the subtree last should be calculated. We obtain the following: for Л1: Сb8*1=28 th.rub; Л2: Сb1*2=19 th. rub; Л3: $\mathrm{Cbi}^{\star} 3=\infty$ th.rub; Л4: $\mathrm{Cbi}^{*} 4=\infty$ th.rub; Л5: $\mathrm{Cb} 7{ }^{*} 5=22$ th.rub; $\pi 6: \mathrm{Cb} 2^{*} 6=36$ th. rub; $\mathrm{Cb} 3^{*} 6=32$ th.rub; Л7: $\mathrm{Cb}^{*} 7=23$ th.rub; Л8: $\mathrm{Cb}^{*} 8=19$ th.rub; Л9: $\mathrm{Cb}^{*} 9=21$ th. rub; $\mathrm{Cb} 7^{*} 9=19$ th. rub; Л10: $\mathrm{Cb}{ }^{*} 10=19$ th.rub ; $C b 6^{*} 10=16$ th.rub. The least $\mathrm{Cb}^{*} 10$ value corresponds to the $\mathrm{x} 10$ vertex. This vertex is assigned the $\left[S 6^{*} ; 16\right]$ mark. The building of the first edge $(\Pi \Pi 6 ; Л 10)=\left(x 6^{*}\right.$; $\mathrm{x} 10$ ) is equal to the choice of direction for the first skid road corresponding to the transportation way between the $\Pi \Pi 6$ loading point and the Л10 site. So, we obtain the subtree:

\section{$T S=\left\{x_{1}{ }^{*}, x_{2}{ }^{*}, x_{3}{ }^{*}, x_{4}{ }^{*}, x_{5}{ }^{*}, x_{6}{ }^{*}, x_{7}{ }^{*}, x_{8}{ }^{*}, x_{10}\right\}$,}

where the $x_{10}$ vertex corresponds to the $Л 10$ site (Figure 3a).

Step 3. As a result of the previous addition of the $x_{10}$ vertex to the subtree there appears the $x_{9}$.vertex near the subtree. Now it is accessible from the $x_{4}{ }^{*}, x_{6}{ }^{*}, x_{7}{ }^{*}$ verti-ces. The minimal value of the oriented edge inputting in the $x 9$ vertex is equal to $\mathrm{Cb} 10,9=13$ th.rub., that corresponds to the least value among all calculated values. The $x 9$ ver-tex with the [S10;13] mark is included into the $T S=\left\{x_{1}{ }^{*}, x_{2}{ }^{*}, x_{3}{ }^{*}, x_{4}{ }^{*}, x_{5}{ }^{*}, x_{6}{ }^{*}, x_{7}{ }^{*}, x_{8}{ }^{*}, x_{9}, x_{10}\right\}$ subtree.

Steps $4 \ldots 11$. Continuously acting according to the algorithm we consequently include the vertices into the subtree: $x 8:(S 9 ; 9), x_{7}:(S 8 ; 9,7), x_{5}$ : (S9;12), $x_{4}:(S 5 ; 12), x_{2}:(S 1 ; 19), x_{6}:(S 2 ; 18), x_{3}$ : (S2;24), $x_{1}$ : (S8;28) (Fig.3b).

Step 12. Having calculated the edges output di-rected from the $x_{1}$ vertex connected to the subtree last we deduce $\mathrm{Cb} 15=10$ th.rub. for the $x 5$ vertex. This calculated value is less than the mark deduced for the $x_{5}$ vertex earli-er. In order to improve the mark of the $x_{5}$ vertex it is necessary to remove from the subtree the $\left(x_{9}, x_{5}\right)$ edge corre-sponding to the transportation way between the 79 , 75 sites and to include into the subtree the $\left(\mathrm{x}_{1}, \mathrm{x}_{5}\right)$ edge with the $\left(\mathrm{S}_{1} ; 10\right)$ mark of the $x_{5}$ vertex. The loop is open and the $x_{4}$, vertex connected to the $x_{5}$ vertex earlier by the $\left(x_{5}, x_{4}\right)$ edge loses its mark and is excluded from the TS subtree (Fig.3c). We obtain:

$$
\begin{gathered}
T_{S}=\left\{\begin{array}{l}
x_{1^{*}}, x_{2^{*}}, x_{3^{*}}, x_{4^{*}}, x_{5^{*}}, x_{6^{*}}, x_{7^{*}}, x_{8^{*}}, \\
x_{1}, x_{2}, x_{3}, x_{5}, x_{6}, x_{7}, x_{8}, x_{9}, x_{10}
\end{array}\right\} ; \\
A_{S}=\left\{\begin{array}{l}
\left(x_{1^{*}}, x_{2^{*}}\right),\left(x_{2^{*}}, x_{3^{*}}\right),\left(x_{3^{*}}, x_{4^{*}}\right), \\
\left(x_{4^{*}}, x_{5^{*}}\right),\left(x_{5^{*}}, x_{6^{*}}\right), \\
\left.x_{6^{*}}, x_{7^{*}}\right),\left(x_{7^{*}}, x_{8^{*}}\right),\left(x_{6^{*}}, x_{10}\right),\left(x_{10}, x_{9}\right), \\
\left.\left.x_{9}, x_{8}\right), x_{8}, x_{7}\right) \\
\left(x_{1^{*}}, x_{2}\right),\left(x_{2}, x_{6}\right),\left(x_{2}, x_{3}\right), \\
\left(x_{8^{*}}, x_{1}\right),\left(x_{1}, x_{5}\right)
\end{array}\right\} ;
\end{gathered}
$$

Step 13. The following calculations for the edges connecting the $x 5$ vertex with the $x 4$ and $x 9$ vertices allow to make a conclusion about an appropriate modernization of the subtree in the $x 9$ vertex and replacement of the $(x 10, x 9)$ edge for the $(x 5, x 9)$ edge with the $(S 5 ; 10,9)$ mark of the $x 9$ vertex, this implies exclusion of the loop with 
the $x 7, x 8$ vertices, output directed from the $x 9$ vertex, from the TS subtree (Fig. 3d).

Steps $14 \ldots 16$. The following calculations imply a repeated formation of the subtree basing on the consequent connection of the $x 7$ vertex with the minimal $(S 6 ; 9,8)$ mark (Fig. 3e), the vertices: $x 8$ : $(S 7 ; 10,4), x 4:(S 5 ; 11,2)$ to it (Fig. $3 f)$.

The shortest spanning tree obtained as a result of calculations looks like as follows:

$T_{S}=\left\{\begin{array}{l}x_{1 *}, x_{2^{*}}, x_{3^{*}}, x_{4^{*}}, x_{5^{*}}, x_{6^{*}}, x_{7^{*}}, x_{8^{*}}, \\ x_{1}, x_{2}, x_{3}, x_{4}, x_{5}, x_{6}, x_{7}, x_{8}, x_{9}, x_{10}\end{array}\right\}$

$A_{S}=\left\{\begin{array}{l}\left(x_{1^{*}}, x_{2^{*}}\right),\left(x_{2^{*}}, x_{3^{*}}\right),\left(x_{3^{*}}, x_{4^{*}}\right), \\ \left(x_{4^{*}}, x_{5^{*}}\right),\left(x_{5^{*}}, x_{6^{*}}\right),\left(x_{6^{*}}, x_{7^{*}}\right), \\ \left.x_{7^{*}}, x_{8^{*}}\right),\left(x_{6^{*}}, x_{10}\right),\left(x_{1^{*}}, x_{2}\right), \\ \left.x_{2}, x_{3}\right),\left(x_{2}, x_{6}\right),\left(x_{6}, x_{7}\right), \\ \left(x_{7}, x_{8}\right),\left(x_{8^{*}}, x_{1}\right),\left(x_{1}, x_{5}\right), \\ \left(x_{5}, x_{4}\right),\left(x_{5}, x_{9}\right)\end{array}\right\}$.

Thus, the analysis of the eight variants of the loading point distribution on the territory of the forest compartment resulted in the conclusion that only three of these variants can be characterized as a rational placing, effective and sufficient enough (Fig.4); as well this analy-sis showed the best directions for skid road construction corresponding to the criterion of reducing the costs for the forest compartment development. In the example analyzed the total minimal construction costs for loading points, skid roads and timber skidding during the development of the whole forest compartment make:

$C_{b}=\sum C_{b i j}=157$ th.rub.

Therefore, the proposed technique allows by us-ing the algorithm to obtain a rational variant of transportation way distribution in the forest compartment, to reduce the construction costs for loading points, transportation ways and timber skidding using these ways for $18 \%$, while the calculated cost advantage of the algorithm usage makes $26 \mathrm{rub} . / \mathrm{m}^{3}$.
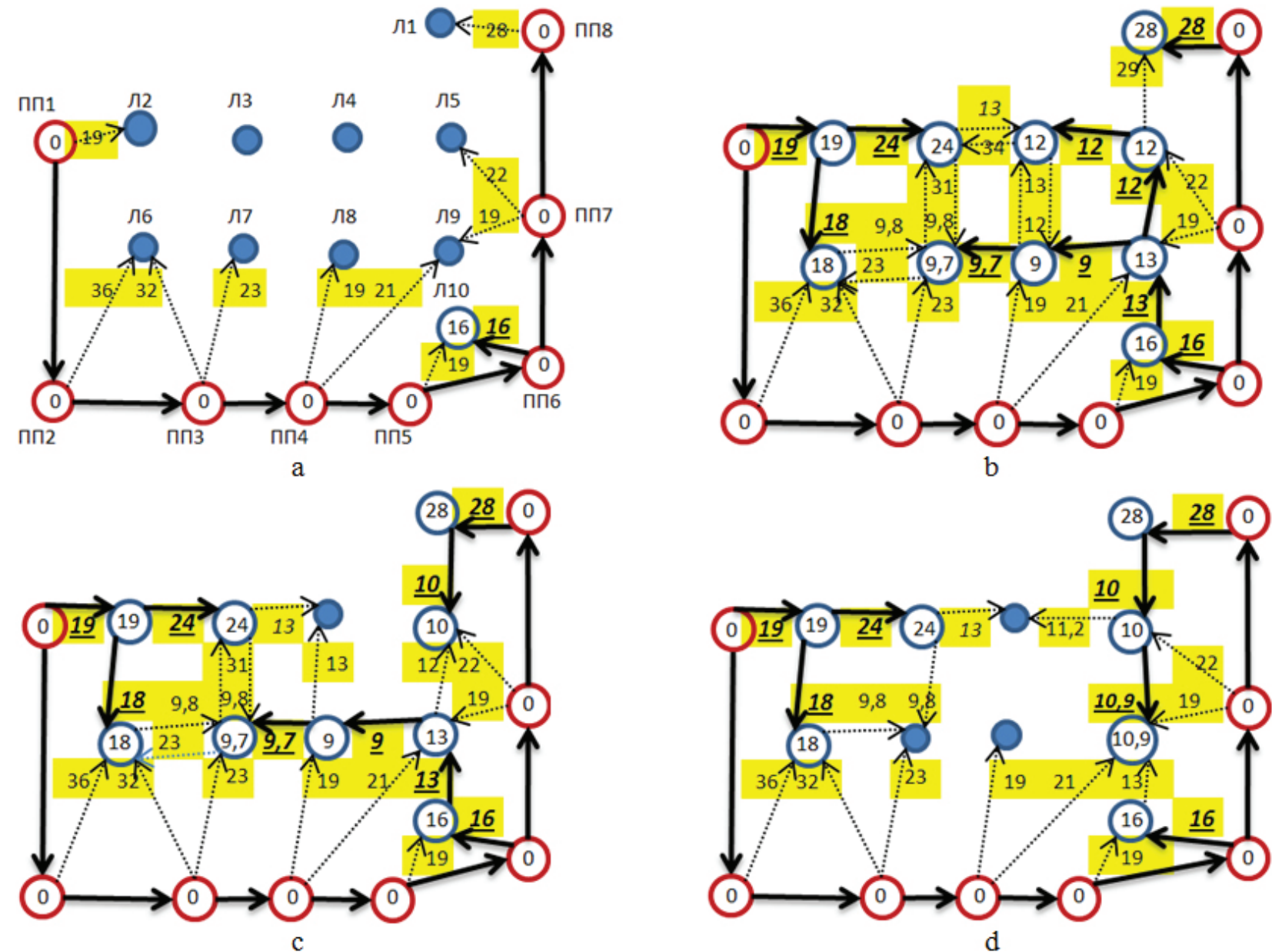

Figure 3. An example algorithm for structuring of loading points and skid roads within a forest compartment 


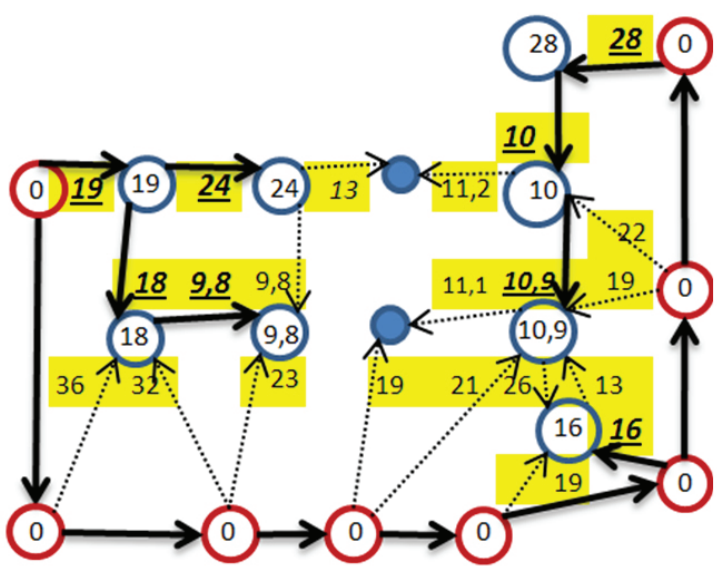

e

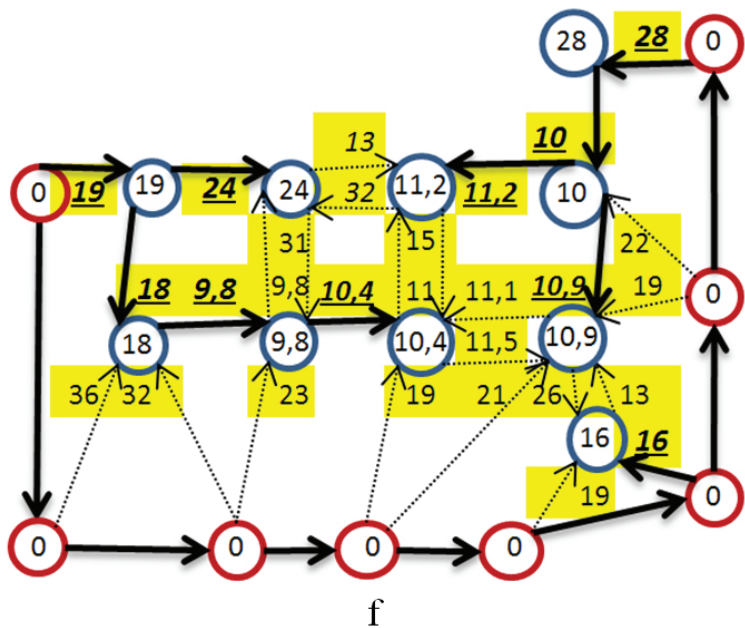

Figure 3. An example algorithm for structuring of loading points and skid roads within a forest compartment

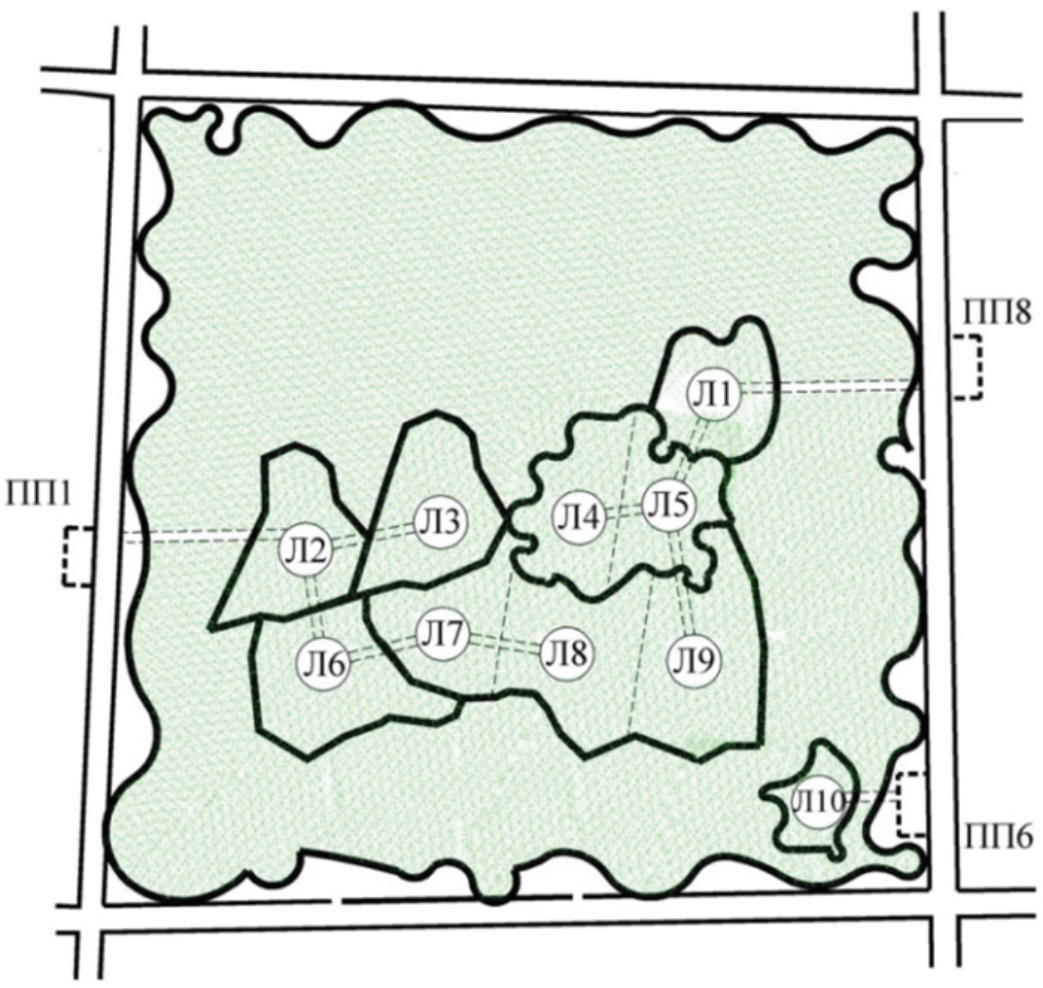

Figure 4. The results of choosing a distribution scheme of the transportation way son the territory of the forest compartment

\section{ACKNOWLEDGEMENT}

The article was prepared as part of research work №1 of base part of the state task of Volga State University of Technology.

\section{REFERENCES}

1) K.P. Rukomojnikov. 2013, Technical and technological aspects of progressive cutting forest com-partment with combined reforestation. World Applied Sciences Journal. Volume 24, Issue 11: 1429-1434.
2) K.P. Rukomojnikov. 2014. Graphic-analytical approach to rationale of placing secondary road on territory of forest compartment. Modern problems of science and education. №6: http://www.science-education.ru/120-16418

3) K.P. Rukomojnikov. 2014. Graphic-analytical modeling of technology of forest harvesting in forest com-partment with fuzzy dynamic natural production condi-tions. Modern problems of science and education. №6: http:// www.science-education.ru/120-16417 
4) K.P. Rukomojnikov. 2014. Justification sequences to perform basic transport operations of logging operations during harvesting within the forest compart-ment. Modern problems of science and education. №6: http://www.science-education.ru/120-16401

5) K.P. Rukomojnikov. 2015. Structuring of loading points and main skid road in the forest compart-ment. Modern problems of science and education. №1: http://www.science-education.ru/121-19239

6) K.P. Rukomojnikov. 2007. Substantiation of a technique of account the basic technological parameters within the planning quarter borders. Moscow state forest university bulletin — Lesnoy vestnik. №4(53): 96-102.

7) A.V. Makarenko. 2013. Software design skidding trails on the cutting area. Moscow state forest univer-sity bulletin. Lesnoy vestnik. №1(93): 99-104.
8) I.R.Shegelman, A.V.Kuznecov, V.I.Skrypnik, and V.N.Baklagin 2012. The method of optimization of development transport and technological of forest re-sources. Engineering Journal of Don. №4-2(23): Page 35;

9) D.N. Afonichev. 2009. The stub spur road arrangement on the cutting area. Moscow state forest uni-versity bulletin - Lesnoy vestnik. № 3: 92-94.

10) D.N. Afonichev, Danilov A. D. and Petrovsky V.S. 2014. Mathematical software of CAD systems of facilities of industrial and transport infrastructure in timber industry. Lesotexnicheskij zhurnal. Volume 4. № 1 (13): 75-80.

Paper sent to revision: 18.08.2015.

Paper ready for publication: 15.09.2015. 